\title{
Study of Apparent Diffusion Coefficient Changes According to Spinal Disease in MR Diffusion-weighted Image
}

\author{
Yeong-Cheol Heo ${ }^{1}$ and Jae-Hwan Cho ${ }^{2 *}$ \\ ${ }^{1}$ Department of Radiological Science, College of Health Sciences EulJi University, Seongnam 13135, Korea \\ ${ }^{2}$ Department of Radiological Technology, Ansan University, Ansan 15518, Korea
}

(Received 1 February 2017, Received in final form 16 February 2017, Accepted 16 February 2017)

\begin{abstract}
In this study, we compared the standardized value of each signal intensity, the apparent diffusion coefficient (ADC) that digitizes the diffusion of water molecules, and the signal to noise ratio (SNR) using b value 0400 , $1400\left(\mathrm{~s} / \mathrm{mm}^{2}\right)$. From March 2013 to December 2013, patients with suspicion of simple compound fracture and metastatic spine cancer were included in the MR readout. We used a 1.5 Tesla Achieva MRI system and a SynSpine Coil. Sequence is a DWI SE-EPI sagittal (diffusion weighted imaging spin echo-echo planar imaging sagittal) image with b-factor $\left(\mathrm{s} / \mathrm{mm}^{2}\right) 0,400,1400$ were used. Data analysis showed ROI (Region of Interest) in diseased area with high SI (signal intensity) in diffusion-weighted image b value $0\left(\mathrm{~s} / \mathrm{mm}^{2}\right)$ Using the MRIcro program, each SI was calculated with images of b-value 0,400 , and $1400\left(\mathrm{~s} / \mathrm{mm}^{2}\right)$, ADC map was obtained using Metlab Software with each image of b-value, The ADC is obtained by applying the ROI to the same position. The standardized values $\left(\mathrm{SI}_{400} / \mathbf{S I}_{0}, \mathbf{S I}_{400} / \mathbf{S I}_{0}\right)$ of simple compression fractures were $0.47 \pm 0.04$ and $0.23 \pm 0.03$ and the standardized values $\left(\mathrm{SI}_{400} / \mathbf{S I}_{0}, \mathbf{S I}_{400} / \mathbf{S I}_{0}\right)$ of the metastatic spine were $0.57 \pm 0.07$ and $0.32 \pm 0.08$ And the standardized values of the two diseases were statistically significant $(p<0.05)$. The ADC $\left(\mathrm{mm}^{2} / \mathrm{s}\right)$ for b value $400\left(\mathrm{~s} / \mathrm{mm}^{2}\right)$ and $1400\left(\mathrm{~s} / \mathrm{mm}^{2}\right)$ of the simple compression fracture disease site were $1.70 \pm$ 0.16 and $0.93 \pm 0.28$ and $1.24 \pm 0.21$ and $0.80 \pm 0.15$ for the metastatic spine. The $A D C\left(\mathrm{~mm}^{2} / \mathrm{s}\right)$ for $b$ value 400 $\left(\mathrm{s} / \mathrm{mm}^{2}\right)$ was statistically significant $(\mathrm{p}<0.05)$ but the ADC $\left(\mathrm{mm}^{2} / \mathrm{s}\right)$ for $b$ value $1400(p>0.05)$. In conclusion, multi - $b$ value recognition of signal changes in diffusion - weighted imaging is very important for the diagnosis of various spinal diseases.
\end{abstract}

Keywords: Apparent Diffusion Coefficient (ADC), B value, Diffusion weighted imaging (DWI)

\section{Introduction}

Magnetic resonance imaging (MRI) has been reported to be sensitive for the diagnosis of osteoporotic complications such as compression fracture or insufficiency fracture of the spine [1]. Diffusion weighted images (DWI) were used to visualize the movement of water in the intracellular space. The skeletal muscle damage was detected early in the signal intensity changes of the muscles. Especially, relatively weak damage [2] it has been reported to be useful in the differential diagnosis of benign and malignant spinal compression fractures [3-6]. In order to obtain a diffusion-weighted image, a very strong pair of oblique magnetic fields, that is, a diffusion gradient oblique magnetic field, is used in addition to the oblique magnetic

(C)The Korean Magnetics Society. All rights reserved.

*Corresponding author: Tel: +82-31-400-6941

Fax:+82-31-363-7703, e-mail: 8452404@hanmail.net field, which is normally used for obtaining an image. The integral of the intensity and time of the diffusion gradient gradient magnetic field is called a gradient factor or $b$ value, and the diffusion-emphasized image can be obtained as the number of inclinations increases [7]. The apparent diffusion coefficient (ADC) is the numerical value of the degree of diffusion of water [8]. Diffusion-weighted images show early changes in muscle signal intensity when skeletal muscle damage is present and have been reported to be useful in the differential diagnosis of benign and malignant spinal compression fractures. However, is not reported much. In order to investigate the changes of simple compression fracture and metastatic spine cancer according to $b$ value, the normalized value of each signal intensity and the diffusion degree of water molecule were measured using $\mathrm{b}$ value $0,400,1400\left(\mathrm{~s} / \mathrm{mm}^{2}\right)$ and the signal-to-noise ratio (SNR). 

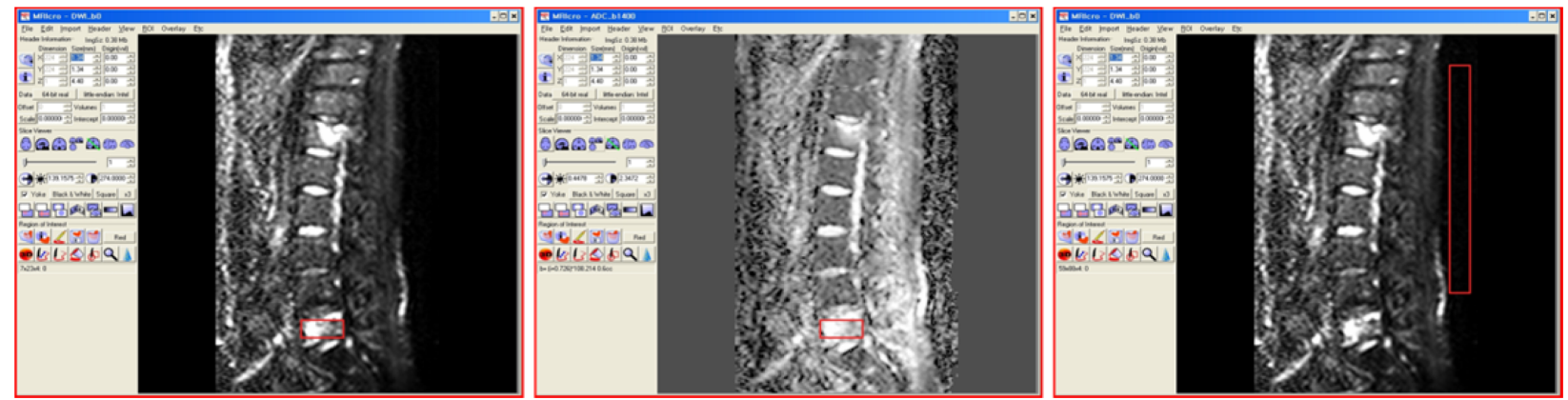

Fig. 1. (Color online) Diffusion-weighted images of each b-value and ADC map were used to plot the ROI on the diseased area and background.

\section{Subjects and Method}

From March 2013 to December 2013, 22 patients were enrolled in the medical records of patients suspected of having a simple compound fracture and metastatic spine cancer. The mean age of the patients was 11 71.2, 56.6. The test equipment was a 1.5 Tesla Achieva MRI system (Philips Healthcare, Netherlands) and a Syn-Spine Coil (Philips Healthcare, Netherlands). Sequence is a DWI SEEPI sagittal (diffusion weighted imaging spin echo-echo planar imaging sagittal) image with TR (ms) 1988, TE (ms) 68, FOV $(\mathrm{mm}) 128 \times 128$, thickness $(\mathrm{mm}) 4$, gap (mm) 0.4, Slice 13, b-factor $\left(\mathrm{s} / \mathrm{mm}^{2}\right)$ 0, 400, 1400 were used. Data analysis showed ROI (Region of Interest) in diseased area with high SI (signal intensity) in diffusion weighted image $b$ value $0\left(\mathrm{~s} / \mathrm{mm}^{2}\right)$. Using the MRIcro program, each SI was calculated with images of b-value 0,400 , and $1400\left(\mathrm{~s} / \mathrm{mm}^{2}\right)$, ADC map was obtained using Metlab Software with each image of b-value, and the ADC was obtained by applying the ROI to the same position (Fig. 1). Data analysis was performed by standardizing SI of 400 and $1400\left(\mathrm{~s} / \mathrm{mm}^{2}\right)$ according to $\mathrm{b}$ value 0 for the first two diseases $\left(\mathrm{SI}_{400} / \mathrm{SI}_{0}, \mathrm{SI}_{400} / \mathrm{SI}_{0}\right)$ Respectively. The equation for obtaining the signal to noise ratio applied to this experiment is as follows.

$$
\mathrm{SNR}=\frac{\text { SI regrion, surrounding tissues }}{\mathrm{SDN}}
$$

SDN : The standard deviation of noise in background SI : signal intensity
The difference of the mean value of the SNR and the mean diffusion coefficient obtained by each $b$ value and the mean value of the signal - to - noise ratio and the diffusivity coefficient by disease were measured by the independent $\mathrm{T}$ test (SPSS win 18.0). $(\mathrm{P}<0.05)$

\section{Result}

The standardized values $\left(\mathrm{SI}_{400} / \mathrm{SI}_{0}, \mathrm{SI}_{400} / \mathrm{SI}_{0}\right)$ of simple compression fractures were $0.47 \pm 0.04$ and $0.23 \pm 0.03$ and the standardized values of $\mathrm{SI}_{400} / \mathrm{SI}_{0}$ and $\mathrm{SI}_{400} / \mathrm{SI}_{0}$ of the metastatic spine were $0.57 \pm 0.07$ and $0.32 \pm 0.08$. The mean value of standardized values was statistically significant $(\mathrm{p}<0.05)($ Table 1,2$)$. The ADC $\left(\mathrm{mm}^{2} / \mathrm{s}\right)$ for $\mathrm{b}$ value $400\left(\mathrm{~s} / \mathrm{mm}^{2}\right)$ and $1400\left(\mathrm{~s} / \mathrm{mm}^{2}\right)$ of the simple compression fracture disease site were $1.70 \pm 0.16$ and $0.93 \pm 0.28$ and $1.24 \pm 0.21$ and $0.80 \pm 0.15$ for the metastatic spine.

The ADC $\left(\mathrm{mm}^{2} / \mathrm{s}\right)$ for b value $400\left(\mathrm{~mm}^{2} / \mathrm{s}\right)$ was statistically significant $(\mathrm{p}<0.05)$ but the ADC $\left(\mathrm{mm}^{2} / \mathrm{s}\right)$ for $b$ value $1400(p>0.05)$. The SNR according to the $b$ value $\left(0 / 400 / 1400\left(\mathrm{~mm}^{2} / \mathrm{s}\right)\right)$ of simple compression fracture and metastatic spine cancer disease was $65.61 \pm 2.61 / 36.32$ $\pm 2.92 / 20.22 \pm 2.16,48.40 \pm 2.72 / 39.27 \pm 7.51 / 23.02$ \pm 6.25 (Table 3, 4) (Fig. 2).

The SNR measurement values according to $b$ value $(0 /$ $\left.400 / 1400\left(\mathrm{~s} / \mathrm{mm}^{2}\right)\right)$ are shown in Table 5.

$B$ value of $400 \mathrm{~s} / \mathrm{mm}^{2}$ was $36.32 \pm 2.92$ for simple compression fractures and $39.27 \pm 7.51$ for metastatic spine cancers. B value of $1400 \mathrm{~s} / \mathrm{mm}^{2}$ was $20.00 \pm 2.16$ for simple

Table 1. Standardized signal intensity of disease site in patients with simple compression fracture.

\begin{tabular}{ccccccccccccc}
\hline \hline & \multicolumn{10}{c}{${\mathrm{SI} / \mathrm{SI}_{0} \text { normalization value }}$} \\
\hline $\begin{array}{c}\text { Signal Intensity } \\
\left.\text { b value (s/mm }{ }^{2}\right)\end{array}$ & 1 & 2 & 3 & 4 & 5 & 6 & 7 & 8 & 9 & 10 & 11 & Average \\
\hline $\mathrm{SI}_{400} / \mathrm{SI}_{0}$ & 0.47 & 0.5 & 0.52 & 0.53 & 0.46 & 0.44 & 0.53 & 0.44 & 0.42 & 0.4 & 0.46 & $0.47 \pm 0.04$ \\
$\mathrm{SI}_{1400} / \mathrm{SI}_{0}$ & 0.23 & 0.26 & 0.25 & 0.26 & 0.22 & 0.21 & 0.26 & 0.19 & 0.22 & 0.18 & 0.23 & $0.23 \pm 0.03$ \\
\hline
\end{tabular}


Table 2. Standardized signal intensity of disease site in patients with metastatic spine cancer.

\begin{tabular}{cccccccccccccc}
\hline \hline & \multicolumn{10}{c}{${\mathrm{SI} / \mathrm{SI}_{0} \text { normalization value }}$} \\
\hline $\begin{array}{c}\text { Signal Intensity } \\
\text { b value (s/mm })\end{array}$ & 1 & 2 & 3 & 4 & 5 & 6 & 7 & 8 & 9 & 10 & 11 & Average \\
\hline $\mathrm{SI}_{400} / \mathrm{SI}_{0}$ & 0.53 & 0.52 & 0.59 & 0.5 & 0.55 & 0.6 & 0.48 & 0.71 & 0.54 & 0.6 & 0.7 & $0.57 \pm 0.07$ \\
$\mathrm{SI}_{1400} / \mathrm{SI}_{0}$ & 0.26 & 0.26 & 0.3 & 0.27 & 0.28 & 0.35 & 0.23 & 0.49 & 0.24 & 0.35 & 0.43 & $0.32 \pm 0.08$ \\
\hline
\end{tabular}

Table 3. Apparent diffusion coefficient of the normal and diseased parts of simple compression fracture patients.

\begin{tabular}{|c|c|c|c|c|c|c|c|c|c|c|c|c|c|}
\hline \multicolumn{14}{|c|}{$\mathrm{ADC}\left(\mathrm{mm}^{2} / \mathrm{s}\right)$} \\
\hline $\mathrm{b}$ value $\left(\mathrm{s} / \mathrm{mm}^{2}\right)$ & Part & 1 & 2 & 3 & 4 & 5 & 6 & 7 & 8 & 9 & 10 & 11 & Average \\
\hline 400 & \multirow{2}{*}{ Normal part } & 0.68 & 0.73 & 0.65 & 0.88 & 0.42 & 0.38 & 0.39 & 0.59 & 0.55 & 0.68 & 0.45 & $0.58 \pm 0.15$ \\
\hline 1400 & & 0.34 & 0.38 & 0.31 & 0.55 & 0.24 & 0.23 & 0.29 & 0.3 & 0.44 & 0.34 & 0.22 & $0.33 \pm 0.09$ \\
\hline 400 & \multirow{2}{*}{ Diseased part } & 1.67 & 1.53 & 1.42 & 1.56 & 1.72 & 1.98 & 1.57 & 1.78 & 1.91 & 1.81 & 1.78 & $1.70 \pm 0.16$ \\
\hline 1400 & & 0.96 & 0.95 & 0.86 & 0.96 & 1.13 & 1.14 & 0.96 & 1.13 & 1.07 & 0.99 & 0.1 & $0.93 \pm 0.28$ \\
\hline
\end{tabular}

Table 4. Apparent diffusion coefficient of the normal and diseased parts of metastatic spine cancer.

\begin{tabular}{|c|c|c|c|c|c|c|c|c|c|c|c|c|c|}
\hline \multicolumn{14}{|c|}{$\mathrm{ADC}\left(\mathrm{mm}^{2} / \mathrm{s}\right)$} \\
\hline & $\mathrm{b}$ value $\left(\mathrm{s} / \mathrm{mm}^{2}\right)$ & 1 & 2 & 3 & 4 & 5 & 6 & 7 & 8 & 9 & 10 & 11 & Average \\
\hline 400 & \multirow{2}{*}{ Normal part } & 0.43 & 0.35 & 0.84 & 0.6 & 0.7 & 0.55 & 0.8 & 0.84 & 0.95 & 0.48 & 0.63 & $0.65 \pm 0.18$ \\
\hline 1400 & & 0.2 & 0.32 & 0.44 & 0.31 & 0.3 & 0.35 & 0.5 & 0.3 & 0.5 & 0.24 & 0.27 & $0.34 \pm 0.1$ \\
\hline 400 & \multirow{2}{*}{ Diseased part } & 1.5 & 1.34 & 1.5 & 1.24 & 0.91 & 1.04 & 1.4 & 1.1 & 1.49 & 1.11 & 0.97 & $1.24 \pm 0.21$ \\
\hline 1400 & & 1 & 0.73 & 0.98 & 0.75 & 0.67 & 0.7 & 1 & 0.7 & 0.95 & 0.7 & 0.57 & $0.80 \pm 0.15$ \\
\hline
\end{tabular}

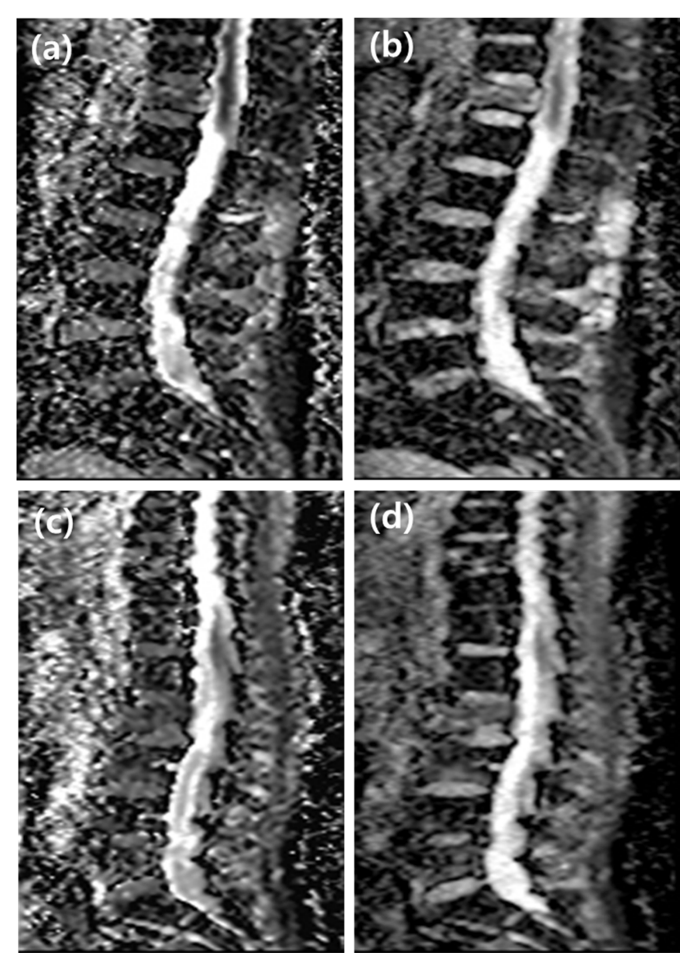

Fig. 2. In patients with simple fractures, ADC map images of $b$ values of $400 \mathrm{~s} / \mathrm{mm}^{2}$ (a) and $1400 \mathrm{~s} / \mathrm{mm}^{2}$ (b), and ADC map images of b values $400 \mathrm{~s} / \mathrm{mm}^{2}$ (c) and $1400 \mathrm{~s} / \mathrm{mm}^{2}$ (d) in metastatic spine cancer patients. compression fracture and $23.02 \pm 6.25$ for metastatic spine. In conclusion, the SNR values according to diseasespecific $b$ values were higher in metastatic spinal cancers $(\mathrm{p}<0.05)$ (Fig. 3).

\section{Discussion}

In order to obtain a diffusion-weighted image, a very strong pair of oblique magnetic fields, that is, a diffusion gradient oblique magnetic field, is used in addition to the oblique magnetic field, which is normally used for obtaining an image. The integral of intensity and time of the diffusion gradient gradient magnetic field is called a gradient factor or $b$ value, and a diffusion-emphasized image can be obtained as the number of inclinations increases. In other words, the larger the diffusion coefficient of the tissue, and the larger the number of inclinometers used, the greater the signal degradation due to diffusion [9-13]. Generally, a b value of about $400 \mathrm{~s} / \mathrm{mm}^{2}$ can be imaged during spinal examination to image the signal loss due to diffusion. Rho [14] et al. measured the signal intensity in diffusion-weighted images by using $b$ value of $150 \mathrm{~s} / \mathrm{mm}^{2}$ in patients with vertebral fractures classified into four categories such as acute osteoporosis, metastasis, chronic osteoporosis and spondylitis. On MRI, metastatic compression fractures and spondylitis have high signal intensity, 
Table 5. Signal to noise ratio of simple compression fracture patients and metastatic spine cancer patients.

\begin{tabular}{cccccccccccccc}
\hline \hline & & \multicolumn{10}{c}{ SNR } \\
\hline $\begin{array}{c}\mathrm{b} \text { v value } \\
\left(\mathrm{s} / \mathrm{mm}^{2}\right)\end{array}$ & Disease & 1 & 2 & 3 & 4 & 5 & 6 & 7 & 8 & 9 & 10 & 11 & Average \\
\hline 0 & Simple & 68.02 & 69.52 & 62.45 & 67.9 & 68.54 & 64.19 & 62.89 & 66.58 & 65.02 & 65.46 & 61.17 & $65.61 \pm 2.61$ \\
400 & compression & 33.61 & 34.89 & 33.43 & 36.73 & 40.85 & 33.58 & 42.67 & 37.88 & 35.91 & 35.73 & 34.27 & $36.32 \pm 2.92$ \\
1400 & fracture & 16.77 & 20.72 & 18.48 & 20.44 & 21.79 & 17.72 & 24.47 & 18.18 & 19.57 & 22.4 & 19.43 & $20.00 \pm 2.16$ \\
\hline 0 & Metastatic & 50.95 & 47.56 & 48.65 & 48.03 & 47.98 & 46.57 & 45.04 & 52.34 & 47.7 & 45.77 & 51.76 & $48.40 \pm 2.27$ \\
400 & spine & 34.1 & 49.72 & 40.37 & 33.14 & 49.89 & 35.37 & 29.16 & 42.67 & 28.1 & 41.51 & 47.89 & $39.27 \pm 7.51$ \\
1400 & cancer & 16.68 & 26.12 & 21.49 & 20.86 & 28.36 & 21.69 & 15.31 & 31.29 & 11.92 & 30.57 & 28.92 & $23.02 \pm 6.25$ \\
\hline
\end{tabular}
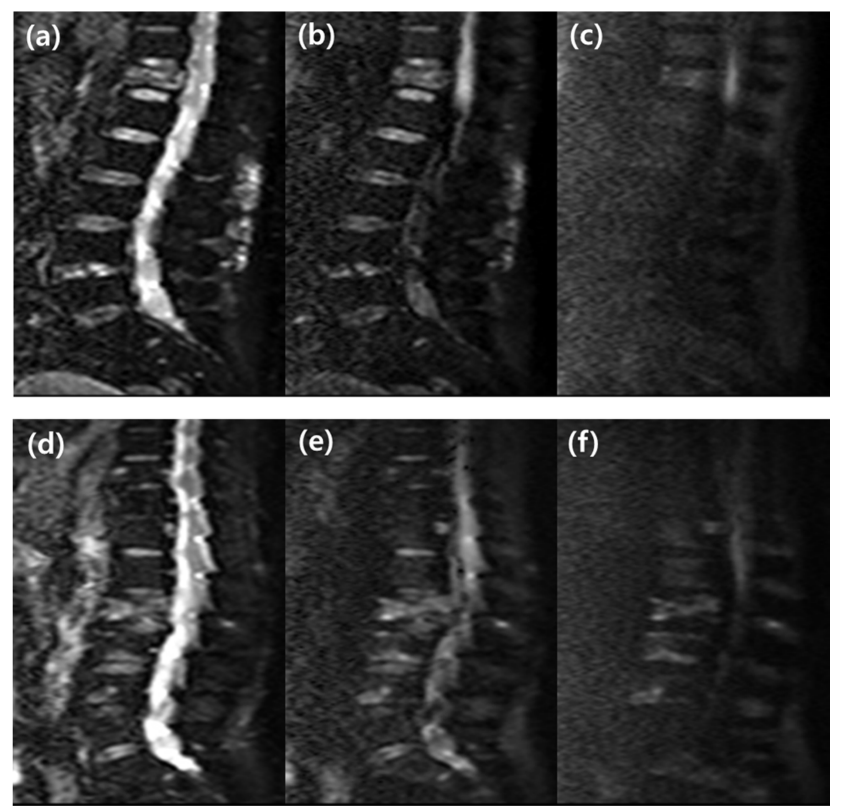

Fig. 3. In patients with simple fractures, DW images of b values of $0 \mathrm{~s} / \mathrm{mm}^{2}$ (a), $400 \mathrm{~s} / \mathrm{mm}^{2}$ (b) and $1400 \mathrm{~s} / \mathrm{mm}^{2}$ (c), and DW images of b values $0 \mathrm{~s} / \mathrm{mm}^{2}(\mathrm{~d}), 400 \mathrm{~s} / \mathrm{mm}^{2}(\mathrm{e})$ and 1400 $\mathrm{s} / \mathrm{mm}^{2}$ (f) in metastatic spine cancer patients.

acute osteoporotic compression fractures have low signal intensity, and chronic osteoporotic compression fractures show various signal intensities. However, they did not mention the difference in signal intensity in diffusionweighted images due to changes in b Value. In this study, patients with high signal intensity among patients with chronic osteoporotic fracture based on b value of $400 \mathrm{~s} /$ $\mathrm{mm}^{2}$ were studied. The difference of signal-to-noise ratio according to the change of $b$ value and the signal-to- The differences were studied. DeLano et al. [9] reported that signal intensity decreased in white matter and granule as $\mathrm{b}$ value increased in normal brain. In this study, $\mathrm{b}$ value of $0,400,1400\left(\mathrm{~s} / \mathrm{mm}^{2}\right)$ was used and there was a clear difference between the standardized value and the present diffusivity at $b$ value $400\left(\mathrm{~s} / \mathrm{mm}^{2}\right)$. In conclusion, it is suggested that the use of diffusely weighted diffusivity in various spine diseases will be helpful for accurate diagnosis in addition to general spinal MRI. We could not apply various $b$ values as a limitation of this study. We did not establish sex, age, stage and stage of each disease, and the first onset of metastatic cancer. The conclusions drawn from the data where high signal intensities are derived should be supplemented in the future.

\section{Conclusion}

The use of Multi - $b$ value for the detection of signal changes in diffusion - weighted imaging is very important for the diagnosis of various spinal diseases.

\section{References}

[1] J. S. Moon and K. C. Won, Yeungnam Univ. J. of Med. 25, 19 (2008).

[2] K. J. Kim, J. Korean Radiol. Soc. 42, 175 (2000).

[3] A. Baur, A. Stäbler, R. Brüning, R. Bartl, A. Krödel, M. Reiser, and M. Deimling, Radiology. 207, 349 (1998).

[4] R. Abanoz, B. Hakyemez, and M. Parlak, Tani Girisim Radyol. 9, 176 (2003).

[5] A. Biffar, A. Baur-Melnyk, G. P. Schmidt, M. F. Reiser, and O. Dietrich, Invest Radiol. 46, 601 (2011).

[6] A. Baur, A. Stabler, A. Huber, and M. Reiser, Semin Musculoskelet Radiol. 5, 35 (2001).

[7] J. H. Lee, J. Korean Radiol. Soc. 49, 455 (2003).

[8] D. Chien, K. K. Kwong, D. R. Gress, F. S. Buonanno, R. B. Buxton, and B. R. Rosen, AJNR Am. J. Neuroradiol. 13, 1097 (1992).

[9] M. C. DeLano, T. G. Cooper, J. E. Siebert, M. J. Potchen, and K. Kuppusamy, AJNR Am. J. Neuroradiol. 21, 1830 (2000).

[10] J. H. Burdette, D. D. Durden, A. D. Elster, and Y. F. Yen, J. Comput. Assist. Tomogr. 25, 515 (2001).

[11] Y. C. Heo, H. K. Lee, and J. H. Cho, J. Magn. 18, 422 (2013).

[12] Y. J. Lee, M. H. Choi, H. J. Goh, and D. K. Han, J. Magn. 21, 281 (2013).

[13] A. R. Cho, H. K. Lee, H. J. Yoo, and C. S. Park, J. Magn. 20, 381 (2015).

[14] B. H. Rho, J. Korean Radiol. Soc. 43, 349 (2000). 